\title{
Effect of Hormones on Direct Shoot Regeneration in Hypocotyl Explants of Tomato
}

\author{
Rizwan RASHID, Sarbjit Singh BAL \\ Punjab Agricultural University, Department of Vegetable Crops, Ludhiana 141004, India; rizwan60@gmail.com, drssbal@yahoo.co.in
}

\begin{abstract}
This study was conducted for developing a high frequency regeneration system in two genotypes of tomato (Lycopersicon esculentum Mill.), 'Punjab Upma' and 'IPA-3' for direct shoot regeneration from hypocotyl explants. The explants were excised from in vitro tomato seedlings and cultured on MS medium supplemented with different concentrations and combinations of hormones. Direct regeneration was significantly influenced by the genotype hormones combination and concentrations. The MS medium supplemented with (Kinetin $0.5 \mathrm{mg} / \mathrm{l}$ ) and (BAP $0.5 \mathrm{mg} / \mathrm{l}$ ) was found optimum for inducing direct shoot regeneration and number of shoots per explant from hypocotyl explants on this medium. Shoot regeneration per cent in 'Punjab Upma' and 'IPA-3' per cent was recorded to be highest i.e (86.02) and (82.57) respectively. Besides this, average number shoots per explant was also highest i.e (3.16) in case of 'Punjab Upma' and (2.93) in case of 'IPA-3'. A significant decline was observed in percent shoot regeneration and average number of shoots per explant with increase in the hormonal concentration. Shoots were obtained and transferred to the elongation medium (MS + BAP $0.3 \mathrm{mg} / \mathrm{l})$. Hundred per cent rooting was induced in separated shoots upon culturing on MS and $1 / 2 \mathrm{MS}$ basal media. Hardening on moist cotton showed maximum plantlet survival rate in case of both genotypes. After hardening, plants were transferred to soil. Thus, a tissue culture base line was established in tomato for obtaining direct regeneration using hypocotyl as explants.
\end{abstract}

Keywords: Lycopersicon esculentum, in vitro culture, explants, direct regeneration, hormones

\section{Introduction}

Tomato (Lycopersicon esculentum Mill., $2 \mathrm{n}=2 \mathrm{x}=24$ ), belongs to family Solanaceae and is a major vegetable crop. Tomato plays a vital role in maintaining human health and vigour. It is also very helpful in healing wounds because of the antibiotic properties found in the ripe fruit. Tomato is a rich source of Vitamin C, Vitamin B and a good source of $\beta$-carotene (Raziuddin et al., 2004). It is an essential ingredient of most of the vegetarian and non-vegetarian recipes. Tomato is considered as one of the most important vegetable crops for genetic engineering because it serves as a model plant for introduction of agronomically important genes into dicotyledonous crop plants (Wang et al., 1994). To produce improved varieties through tissue culture proper understanding of the hormonal requirements of various morphogenetic phenomena are considered prerequisite for the success (Manzoor 1994). Gene transfer technology is mainly dependent on the availability of explant based regeneration system through tissue culture. In vitro regeneration can be difficult to achieve for some plant species or particular genotypes within a species. Among the Lycopersicon species, $L$. peruvianum is considered to be highly organogenetic and regeneration of shoots from roots has already been documented (Koornneeff et al., 2004). Direct regeneration has been reported to vary with concentrations and combina- tions of hormones, light and incubation, genotype and explant used (Bhatia et al., 2004). Therefore, it is important to standardization of culture conditions to achieve direct regeneration in desired genotypes. The present work was carried out to study the direct shoot regeneration capacity of hypocotyl explant on different hormone levels in two genotypes of tomato, 'Punjab Upma' and 'IPA-3'. The protocol thus standardized would be helpful in carrying our genetic transformation experiments in tomato.

\section{Materials and methods}

The investigation was carried out at "Tissue Culture and Genetic Transformation Laboratory" in the School of Agricultural Biotechnology, Punjab Agricultural University, Ludhiana during 2006-2009. Seeds of two tomato genotypes, 'Punjab Upma' and 'IPA-3' were surface sterilized with $2 \%$ sodium hypochlorite solution for $20 \mathrm{~min}$ utes in laminar air flow cabinet and rinsed 3 times with sterile distilled water. Seeds were then germinated on MS medium supplemented with $100 \mathrm{mg} / \mathrm{l}$ myo-inositol and $30 \mathrm{~g} / \mathrm{l}$ sucrose. All cultures were maintained at $25 \pm 2{ }^{\circ} \mathrm{C}$ under $16 \mathrm{~h}$ light (2500 lux) and $8 \mathrm{~h}$ dark periods. Hypocotyls were excised from 15-20 day old seedlings and used as explants for direct regeneration on MS medium supplemented with varying combinations and concentrations of BAP and Kinetin. The observations were recorded on 
per cent direct shoot regeneration, number of shoots per explant, per cent shoot elongation and rooting. The data were analyzed using factorial CRD design.

\section{Results and discussion}

The effect of various combinations and concentrations of hormones (BAP and Kinetin) in cotyledon explants of two tomato genotypes was studied. The excised hypocotyl explants from 15-20 day in vitro germinated seedlings were cultured on Murashige and Skoog (MS 1962) medium supplemented with various combinations and concentrations of BAP and kinetin. No regeneration response was recorded in the explants cultured on basal MS medium. Although plant regeneration could be induced with BAP alone, but combination of BAP and Kinetin enhanced per cent plant regeneration to significantly higher

Tab. 1. Percent direct regeneration from hypocotyl explants after 4 weeks of culture in two genotypes of tomato at different hormone levels

\begin{tabular}{cccccc}
\hline & \multicolumn{2}{c}{$\begin{array}{c}\text { Hormone } \\
(\mathrm{mg} / \mathrm{l})\end{array}$} & \multicolumn{2}{c}{ Direct plant regeneration (\%) } \\
\hline Media & BAP & Kinetin & $\begin{array}{c}\text { 'Punjab } \\
\text { Upma' }\end{array}$ & 'IPA-3' & Mean \\
\hline $\mathrm{T}_{\mathrm{O}}$ & 0.0 & 0.0 & $0.00(0.00)$ & $0.00(0.00)$ & $0.00(0.00)$ \\
$\mathrm{T}_{1}$ & 0.5 & 0.0 & $0.00(0.00)$ & $0.00(0.00)$ & $0.00(0.00)$ \\
$\mathrm{T}_{2}$ & 0.5 & 0.5 & $86.02(68.04)$ & $82.57(65.33)$ & $84.29(66.33)$ \\
$\mathrm{T}_{3}$ & 1.0 & 0.5 & $72.60(58.42)$ & $70.23(56.91)$ & $71.41(57.66)$ \\
$\mathrm{T}_{4}$ & 1.5 & 0.5 & $70.15(56.86)$ & $58.60(49.94)$ & $64.37(53.40)$ \\
$\mathrm{T}_{5}$ & 2.0 & 1.0 & $49.10(44.46)$ & $58.23(49.72)$ & $53.67(47.09)$ \\
$\mathrm{T}_{6}$ & 2.5 & 2.0 & $40.96(39.77)$ & $38.89(38.54)$ & $39.89(39.15)$ \\
$\mathrm{T}_{7}$ & 3.0 & 3.0 & $34.12(35.71)$ & $31.29(33.99)$ & $32.92(34.85)$ \\
$\mathrm{T}_{8}$ & 3.5 & 2.0 & $27.01(31.28)$ & $26.96(31.26)$ & $26.98(31.26)$ \\
$\mathrm{T}_{9}$ & 4.0 & 2.5 & $20.79(27.11)$ & $22.24(28.10)$ & $21.51(28.10)$ \\
\multicolumn{2}{c}{ Mean } & & $40.07(36.16)$ & $38.90(35.38)$ & \\
\hline
\end{tabular}

C.D = Genotypes- 0.69, Hormone concentrations 1.56,

Hormone $\mathrm{x}$ Genotypes-2.20Figures in parenthesis indicates arc since transformation of values

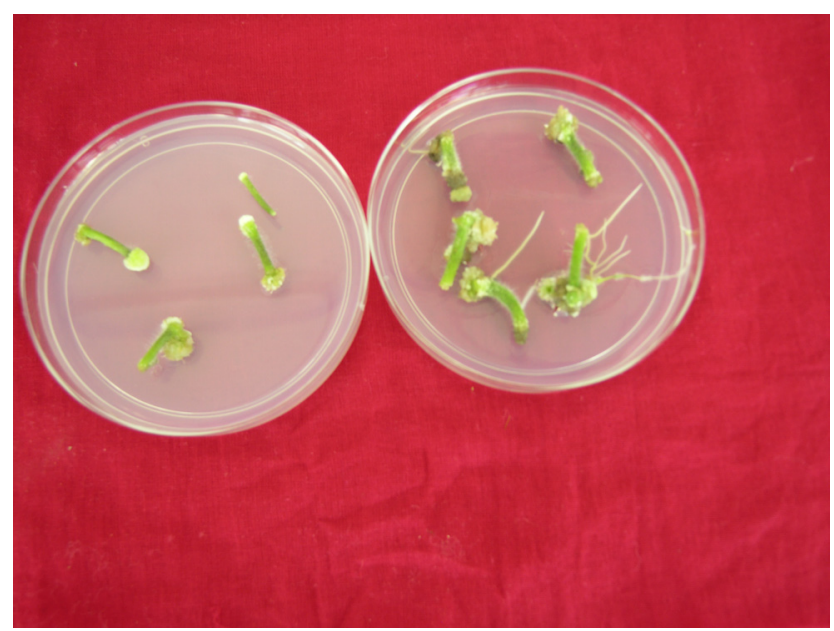

Fig. 1. Hypocotyl explants on MS + 0.5 kinetin + 0.5 BAP levels. The optimal medium for plant regeneration was MS supplemented with $0.5 \mathrm{mg} / \mathrm{l} \mathrm{BAP}$ and $0.5 \mathrm{mg} / \mathrm{l} \mathrm{Ki}-$ netin in both genotypes which was significantly superior over all other combinations (Fig. 1). Per cent regeneration obtained in 'Punjab Upma' and 'IPA-3' was (86.02) and (82.57) respectively. In almost all medium, profuse callus formation was observed. For obtaining maximum shoot regeneration, it was found necessary to subculture the explants on same medium after 15-20 days, otherwise callus formation suppressed shoot regeneration. A significant decline was observed in percent plant regeneration with either increase in the hormonal concentration indicating their inhibitory response on shoot regeneration. Regeneration were obtained on all medium except $T_{O}$ and $\mathrm{T}_{1}$ having no hormone and without kinetin respectively. Although plant regeneration could be induced with BAP alone but combination of BAP and kinetin enhanced per cent plant regeneration to significantly higher levels. The per cent direct regeneration from hypocotyl explants after 4 weeks of culture on different hormone levels is presented in (Tab. 1).

In case of 'Punjab Upma' which varied significantly in all hormonal treatments except $\mathrm{T}_{3}, \mathrm{~T}_{4}$ which shows non-significant differences. In genotype 'IPA-3' also shows significantly variation among the hormonal treatments except $T_{4}, T_{5}$ shows statistically non-significant differences. (Gubis et al., 2004) reported shoot regeneration from hypocotyls on (MS) medium supplemented with $1 \mathrm{mg} / \mathrm{l}$ of zeatin and $0.1 \mathrm{mg} / \mathrm{l}$ of IAA. Similarly (Shivakumar et al., 2007) observed regeneration protocol for tomato cultivars Arka Saurabh and Arka Vikas was developed using cotyledon and hypocotyls explants. Best regenerative response for all the three genotypes was obtained on MS medium supplemented with BAP $2 \mathrm{mg} / \mathrm{l}$ and IAA $0.1 \mathrm{mg} / \mathrm{l}$.

Tab. 2 Average number of shoots from hypocotyl explants after 8 weeks of culture in two genotypes of tomato at different hormone levels

\begin{tabular}{|c|c|c|c|c|c|}
\hline \multirow[b]{2}{*}{ Media } & \multicolumn{2}{|c|}{ Hormone $(\mathrm{mg} / \mathrm{l})$} & \multicolumn{3}{|c|}{$\begin{array}{l}\text { Number of shoots from } \\
\text { hypocotyl explant }\end{array}$} \\
\hline & BAP & Kinetin & $\begin{array}{l}\text { 'Punjab } \\
\text { Upma' }\end{array}$ & 'IPA-3' & Mean \\
\hline $\mathrm{T}_{\mathrm{O}}$ & 0.0 & 0.0 & 0.00 & 0.00 & 0.00 \\
\hline $\mathrm{T}_{1}$ & 0.5 & 0.0 & 0.00 & 0.00 & 0.00 \\
\hline $\mathrm{T}_{2}$ & 0.5 & 0.5 & 3.87 & 2.93 & 3.40 \\
\hline $\mathrm{T}_{3}$ & 1.0 & 0.5 & 3.16 & 2.70 & 2.93 \\
\hline $\mathrm{T}_{4}$ & 1.5 & 0.5 & 2.50 & 2.19 & 2.34 \\
\hline $\mathrm{T}_{5}$ & 2.0 & 1.0 & 1.61 & 1.51 & 1.57 \\
\hline $\mathrm{T}_{6}$ & 2.5 & 2.0 & 1.31 & 1.31 & 1.31 \\
\hline $\mathrm{T}_{7}$ & 3.0 & 3.0 & 1.22 & 1.60 & 1.41 \\
\hline $\mathrm{T}_{8}$ & 3.5 & 2.0 & 1.11 & 1.23 & 1.17 \\
\hline $\mathrm{T}_{9}$ & 4.0 & 2.5 & 1.13 & 1.12 & 1.12 \\
\hline \multicolumn{2}{|c|}{ Mean } & & 1.59 & 1.46 & \\
\hline
\end{tabular}

C.D = Genotypes- 0.71 , Hormone concentrations- 0.16 ,

Hormone x Genotypes- 0.22 
72

The average number of shoots per explant was recorded after 8 weeks of culture. The data is presented in Tab. 2 represents the average number of shoots per explant cultured from the two genotypes of tomato. Shoots were obtained on all media except $T_{O}$ and $T_{1}$ having no hormone and without Kinetin, respectively.

Average number of shoots from hypocotyls explants are presented (Tab. 2).

Shoots were observed after 15-20 days of culture in both the genotypes. The average number of shoots on MS medium supplemented with BAP $0.5 \mathrm{mg} / \mathrm{l}$ and kinetin 0.5 $\mathrm{mg} / \mathrm{l}$ was maximum as compared to other media tested in both genotypes of tomato (Fig. 2). A gradual decrease in number of shoots per explant was recorded when the concentration of hormones increases. Shoots were obtained on all medium except $T_{\mathrm{O}}$ and $\mathrm{T}_{1}$ having no hormone and without kinetin respectively. Shoots were often observed after 15-20 days of culture in both the genotypes Maximum average number of shoots obtained in MS media $\mathrm{T}_{2}$ supplemented with $0.5 \mathrm{mg} / \mathrm{l} \mathrm{BAP}$ and $0.5 \mathrm{mg} / \mathrm{l}$ kinetin in both genotypes i.e 'Punjab Upma' and 'IPA-3'. It was observed that maximum average number of shoots per explant in 'Punjab Upma' (3.87) in medium $\mathrm{T}_{2}$ followed by $\mathrm{T}_{3}$ (3.16) media while in case of 'IPA-3' maximum average number of shoots (2.93) were obtained on $\mathrm{T}_{2}$ followed by $\mathrm{T}_{3}$ medium (2.70). In case of 'Punjab Upma' which var-

Tab. 3. Per cent shoot elongation in two genotypes of tomato 'Punjab Upma' and 'IPA-3' on different culture media

\begin{tabular}{ccc}
\hline \multicolumn{3}{c}{ Shoot elongation (\%) } \\
\hline Culture medium & 'Punjab Upma' & 'IPA-3' \\
\hline MS & 10.25 & 14.25 \\
$1 / 2 \mathrm{MS}$ & 15.23 & 16.25 \\
MS + 0.1 mg/l BAP & 40.25 & 46.23 \\
MS + 0.2mg/l BAP & 60.14 & 65.36 \\
MS + 0.3 mg/l BAP & 89.23 & 91.25 \\
MS + 0.4 mg/l BAP & 74.25 & 75.95 \\
MS + 0.5 mg/l BAP & 70.26 & 71.26 \\
\hline
\end{tabular}

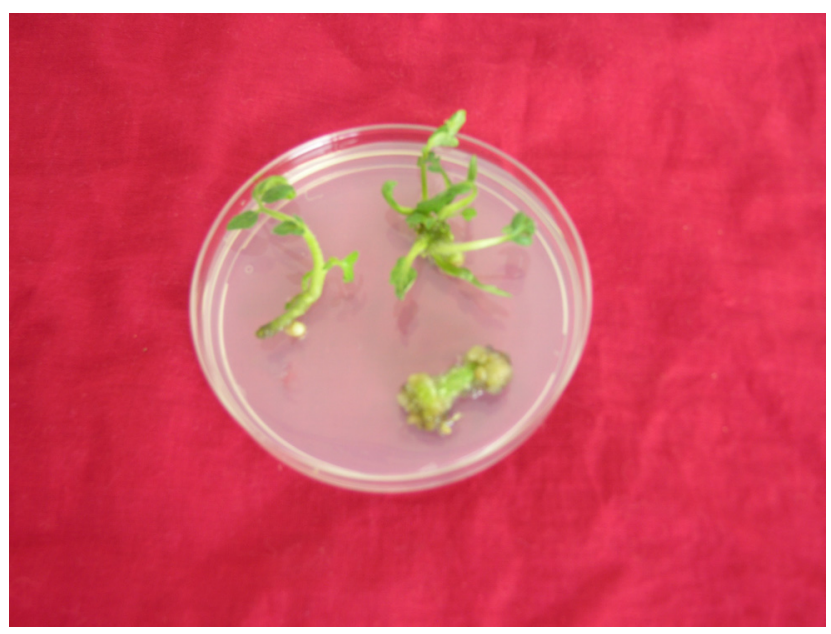

Fig. 2. Hypocotyl explants showing regeneration ied significantly in all hormonal treatments except $\mathrm{T}_{3}$, $\mathrm{T}_{4}$ which shows non-significant differences. In genotype 'IPA-3' also shows significantly variation among the hormonal treatments except $\mathrm{T}_{5}, \mathrm{~T}_{6}$ and $\mathrm{T}_{8}, \mathrm{~T}_{9}$ shows statistically non-significant differences. In case of 'IPA-3' with the increase in hormone the number of shoot decreases but at $\mathrm{T}_{7}$ medium shows higher shoot formation. (Gubis et al., 2003) studied the most responsive explants in most cultivars were hypocotyls and epicotyls with up to $100 \%$ regeneration and mean production of 6.3 and 6.5 shoot primordia per explant respectively.

The shoots obtained on regeneration medium were excised and transferred to the shoot elongation medium.

Tab. 4. Extent of rooting in two genotypes of tomato 'Punjab Upma' and 'IPA-3' on different culture media

\begin{tabular}{ccc}
\hline \multicolumn{3}{c}{ Extent of rooting (\%) } \\
\hline Culture medium & 'Punjab Upma' & 'IPA-3' \\
\hline MS & 100 & 100 \\
$1 / 2 \mathrm{MS}$ & 100 & 100 \\
$\mathrm{MS}+0.2 \mathrm{mg} / \mathrm{l} \mathrm{IBA}$ & 62.12 & 65.16 \\
$1 / 2 \mathrm{MS}+0.2 \mathrm{mg} / \mathrm{l} \mathrm{IBA}$ & 75.15 & 74.12 \\
\hline
\end{tabular}

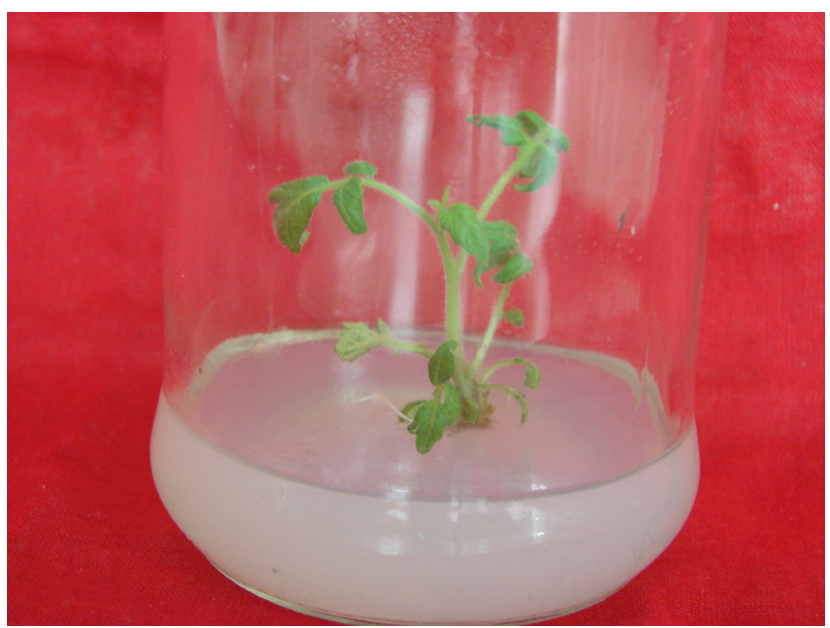

Fig. 3. Hypocotyl explants on elongation medium

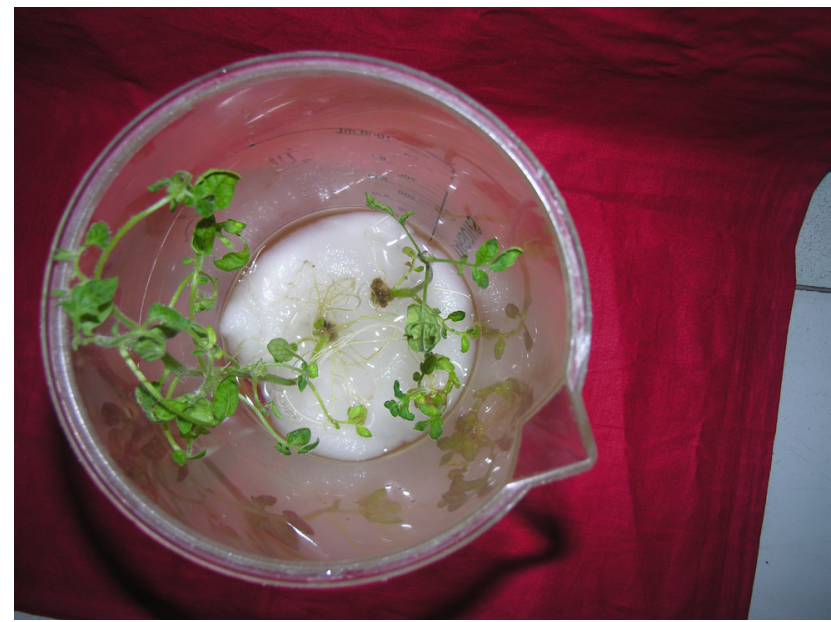

Fig. 4. Hardening of plantlets on moist cotton 


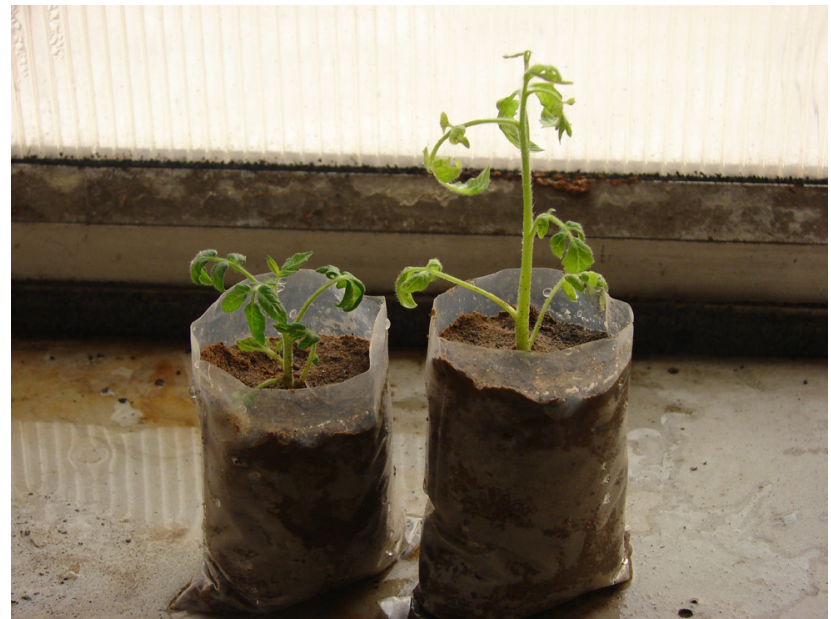

Fig. 5. Hardened plants in glass house

Different media were tried like MS basal medium, 1/2 MS medium and MS basal medium supplemented with different concentrations of BAP presented in (Tab. 3).

The maximum shoot elongation $(89.23 \%$ in 'Punjab Upma' and $91.25 \%$ in 'IPA-3') was seen on MS medium supplemented with BAP $0.3 \mathrm{mg} / \mathrm{l}$ (Fig. 3). Four media compositions as listed in (Tab. 4) were tried for induction of in vitro rooting. The elongated shoots were excised and placed in culture jars containing rooting medium. Root formation occurred within 10-12 days after culturing onto the medium, callus was observed on all rooting media at the base of shoots which inhibited rooting formation. Hundred per cent rooting was recorded on full MS medium and $1 / 2$ MS basal medium in both the genotypes 'Punjab Upma' and 'IPA-3'. In case of 'Punjab Upma', $62.12 \%$ and $75.15 \%$. rooting was also observed in MS medium supplemented with $0.2 \mathrm{mg} / \mathrm{l} \mathrm{IBA}$ and $1 / 2$ MS medium supplemented with $0.2 \mathrm{mg} / \mathrm{l}$ IBA respectively. While in case of 'IPA-3' rooting on above media was $65.16 \%$ and $74.12 \%$ respectively. No genotypic differences were recorded in two genotypes with respect to per cent rhizogenesis. Rooting on the basal MS medium and $1 / 2$ MS media suggested that tomato possesses high levels of endogenous auxins. Therefore, exogenous application of auxins was not required for the induction of in vitro rooting in tomato. Maximum rooting was obtained $92 \%$ when shoots were cultured on MS medium supplemented with zeatin was added at $0.1,0.2,0.5,1.0$, and $2.0 \mathrm{mg} / \mathrm{l}$ (Ouyang et al., 2003).

Tissue culture regenerated plantlets are usually very fragile and mostly die if these are directly transferred to the field because of transplantation shock. As the micro propagated plants are raised in the most congenial environmental conditions, so hardening is imperative to ensure the survival upon transfer to soil under the natural conditions. Regenerated plantlets obtained both from direct regeneration having well developed shoot and root system were removed from the jar and washed thoroughly under running tap water. Hardening of rooted plantlets was done on wet cotton containing ordinary tap water (Fig. 4). The hardened plantlets were then transferred to field soil in polythene bags and kept in glass house (Fig. 5).

\section{Conclusions}

Thus, present investigation thus, an efficient protocol and reproducible for in vitro direct plant regeneration was standardized in tomato. Hypocotyl of 'Punjab Upma' were found to more responsive for direct shoot regeneration as compared to hypocotyl of 'IPA-3'. Direct plant regeneration is a pre-requisite for genetic transformation, for producing transgenic plants.

\section{Acknowledgments}

The financial assistance from the Department of Biotechnology (DBT), Government of India, New Delhi is gratefully acknowledge.

\section{References}

Bhatia, P., N. Ashwath, T. Senaratana and D. J. Midmore (2004). Tissue culture studies in tomato (Lycopersicon esculentum). Pl. Cell Tiss. Organ Cult. 78:1-21.

Gubis, J., Z. Lajchova, J. Farago and Z. Jurekova (2003). Effect of genotype and Explant Type on Shoot Regeneration in Tomato (Lycopersicon esculentum Mill.) in vitro. Czech. J. Genet. Pl. Breed. 39:9-14.

Gubis, J., Z. Lajchova, J. Farago and Z. Jurekova (2004). Effect of growth regulators on shoot induction and plant regeneration in tomato (Lycopersicon esculentum Mill.). Biologia Bratislava 59:405-8.

Koornneeff, M., J. Bade, C. Hanhartc, K. Horsman, J. Schel, W. Soppe, R. Verkerk and P. Zabel (1993). Characterization and mapping of a gene controlling shoot regeneration in tomato. Pl. J. 31:31-41.

Manzoor, A. K. (1994). In-vitro techniques in contemporary plant breeding, Plant Breeding (National Book Foundation), 156-193.

Murashige, T. and F. Skoog (1962). A revised medium for rapid growth and bioassays with tobacco tissue cultures. Physiology Plantarum. 15:473-97.

Ouyang, B., Li-HanXia and Ye-ZhiBiao (2003). Effects of zeatin and IAA on plant regeneration of tomato cotyledon explants. Pl. Physiol Communications. 39:217-218.

Raziuddin, S. S., Shah, H. J. Chaudhary., T. Mohammad and S. Ali (2004). Hormonal effect on callus induction in tomato. Sarhad J. Agri. 20:223-225.

Shivakumar, B., J. B. Mythilli., L. Anand and G. V. S. Saiprasad (2007). Influence of genotype on Agrobacterium-mediated transformation of tomato. Indian J Hort. 64:251-57.

Wang, R. A., H. B. Zhang and S. D. Tanksley (1994). Map based cloning in crop plants: tomato as a model system. Genetic and physical mapping of jointless. Mol. Gen. Genet. 242:681-688. 